\title{
The Characteristics of Runoff Process Structure Changes under the Influence of Climate Change and Human Activities and the Decomposition of Contribution Rate of Impact Factors
}

\author{
Xiaoyuan Song $\mathbb{D}^{1},{ }^{1}$ Zhongyuan $\mathrm{Zhu}^{2}$ XiaoKang $\mathrm{Xi}^{3}{ }^{3}$ Guibin Zhang, ${ }^{1}$ and Hailong Wang $\mathbb{D}^{1}$ \\ ${ }^{1}$ Civil Engineering and Architecture College Linyi University, Linyi 267000, China \\ ${ }^{2}$ Water Conservancy and Civil Engineering College, Inner Mongolia Agricultural University, Hohhot, China 010018 \\ ${ }^{3}$ Shanxi Hydrology and Water Resources Survey Center, Xi'an, China 710000 \\ Correspondence should be addressed to Xiaoyuan Song; yuanxiaosong123@126.com
}

Received 4 December 2020; Revised 18 December 2020; Accepted 22 December 2020; Published 7 January 2021

Academic Editor: Bin Gong

Copyright ( 2021 Xiaoyuan Song et al. This is an open access article distributed under the Creative Commons Attribution License, which permits unrestricted use, distribution, and reproduction in any medium, provided the original work is properly cited.

\begin{abstract}
The research of the runoff structure and its influencing factors in the Xilinhe River Basin not only provides indispensable basic data for the economic development, but also has long-term significance for the protection of grasslands. Based on the runoff data of Xilinhot Hydrological Station from 1960 to 2010 and the daily meteorological data of three surrounding weather stations from 1960 to 2010, the paper calculated the potential evapotranspiration with Penman's formula and used the combination of MannKendall and Pettitt to diagnose the variation points of characteristic value of runoff distribution during the year. The cumulant slope change rate method is used to quantitatively analyze the contribution rate of climate change and human activities to the uneven distribution coefficient and the complete adjustment coefficient of runoff during the year. The results show that (1) the monthly distribution of runoff in the Xilinhe River Basin is obviously "bimodal" during the year, and the uneven coefficient, complete adjustment coefficient, and concentration in the 2000s are significantly higher than those of 60s-90s. (2) In 1998, the coefficient of uneven distribution of runoff in the Xilinhe River Basin and the coefficient of complete adjustment both showed abrupt changes. (3) Climate change and human activities contributed $11.48 \%$ and $88.52 \%$ and $9.35 \%$ and $90.65 \%$ to the uneven distribution coefficient and the complete adjustment coefficient, respectively, of the runoff in the Xilinhe River Basin. Human activities are the main driving factors for changes in the distribution of runoff in the Xilinhe River Basin during the year.
\end{abstract}

\section{Introduction}

Runoff is an important part of hydrology and also critical to the research of surface water resources. Changes in runoff can usually be divided into numerical changes in runoff [19] and structural changes in runoff processes [10]. In recent years, influenced by climate change and human activities, a series of ecological problems appeared in the river runoff, such as the decrease in runoff, shrinkage of rivers, and dry up of downstream rivers [11-14]. Therefore, the studying on runoff changes under the effects of climate change and human activities has certain practical significance. At present, most studies focus on the numerical changes of runoff under the influence of climate change and human activities. For example, Tu et al. [1] studied the changes of runoff in the Bahe Basin of Qinling Mountains and analyzed its influencing factors. Hou et al. [2] studied the runoff changes of the Weihe River in the past 50 years and concluded that human activities are the main reason for its runoff reduction. He et al. [3] studied the contribution rate of climate change and human activities to the change of runoff in the upper and middle reaches of the Heihe River. There are relatively fewer studies on changes in runoff structure. The runoff structure represented by the distribution of runoff during the year has also undergone corresponding changes under the influence of climate change and human activities. The distribution of runoff during the year is not only closely related to droughts and floods, but also water usage sectors, closely related and provides indispensable basic data for the development of the national economy [15-18]. At present, 
among the few studies on the changes in the yearly distribution characteristics of the runoff $[19,20]$, there are very few of them on the changes in the distribution characteristics of the river runoff under the influence of climate change and human activities but only Huang et al. [15] studied quantitatively on the contribution rate of rainfall, potential evapotranspiration, and human activities in the Weihe River Basin runoff concentration and uneven coefficient. However, different basins have different hydrological responses to climate change and human activities. The Xilinhe River Basin is a typical grassland watershed, and studying the distribution characteristics of this area during the year is of great significance for grassland protection.

\section{Data Sources and Research Methods}

2.1. Overview of the Study Area. As shown in Figure 1, the Xilinhe River originates from 12 lakes including Aolun in the Kashkten banner of Chifeng City. It runs through the central part of Xilin Gol League with a total length of 205 kilometers, covering a valley of 1-5 kilometers and a drainage area of 6,263 square kilometers. The upper reaches of the Xilinhe River go up to Cunisuman and flow through the hilly area. The river course is abnormally curved, running from east to the west. The general river valley is $1 \mathrm{~km}$ wide, and the river course is down 1/150-1/400. Below Cunisuman are the middle and lower reaches. The river turns northward, forming a river basin with swamps in between it. The river valley is 2-5 kilometers wide, and for some river sections, it could be as wide as 8 kilometers. The river course is reduced by $1 / 500-1 / 1000$ and in the end goes into Baiyinnur Lake in east Ujumqin Qi.

2.2. Research Data. The digital elevation model (DEM) in this paper is taken from the $1 \mathrm{~km}$ resolution SRTM DEM data of Global Land Cover Facility (http://www.glof.gov). The meteorological data is taken from China Meteorological Data Sharing Service Network (http://cdc.cma.gov.cn). Due to the sparse distribution of meteorological and hydrological stations in the Xilinhe River Basin, this paper has chosen daily meteorological data from 1960 to 2010 from 3 meteorological stations in the Xilinhot Station of Xilinhe River Basin and the surrounding Abaga Qi Station and Linxi Station and Xilinhot Hydrological Station (shown in Figure 1), and meteorological data include rainfall, temperature, maximum temperature, minimum temperature, relative humidity, wind speed, and sunshine hours, and all data have passed the uniformity test of $95 \%$ confidence. Potential evaporation is calculated by Penman's formula. Using ArcGIS spatial interpolation method, the average annual precipitation and average potential evaporation in the basin are obtained, and the monthly and annual values of runoff, rainfall, and potential evaporation are obtained by summing the daily values.

2.3. Research Methods. The calculation formulas for the uneven distribution coefficient $\left(C_{v}\right)$ and the complete adjustment coefficient $\left(C_{r}\right)$ of the meteorological and hydrological distribution during the year $[19,20]$ are as follows:

$$
C_{v}=\frac{\sigma}{\bar{R}}, \sigma=\frac{\sqrt{1 / 12 \sum_{i=1}^{12}\left(R_{i}-\bar{R}\right)^{2}}}{\left[1 / 12 \sum_{i=1}^{12} R_{i}\right]},
$$

where $R_{i}$ is the monthly runoff, rainfall, and evaporation during the year; $\bar{R}$ is the average monthly runoff, rainfall, and evaporation during the year. It can be seen from the formula that the higher the $C_{v}$ value, the larger the difference between monthly runoff, rainfall, and evaporation during the year, meaning more uneven distribution of annual runoff, rainfall, and evaporation. The calculation formula $[19,20]$ of the complete adjustment coefficient for the distribution of runoff, rainfall, and evaporation within the year is as follows:

$$
\begin{gathered}
C_{r}=\frac{\sum_{i=1}^{12} \Psi(t)[R(t)-\bar{R}]}{\sum_{i=1}^{12} R(t)}, \\
\Psi(t)=\left\{\begin{array}{l}
0, R(t)<\bar{R}, \\
1, R(t) \geq \bar{R} .
\end{array}\right.
\end{gathered}
$$

The concentration of runoff is an index to reflect the concentration of annual runoff, and the concentration period is an important indicator to reflect the period of time when the largest runoff occurs in a year. It regards the runoff of each month of the year as a vector, the size of the monthly runoff represents the length of the vector, and the month in which it is located represents the direction of the vector. The monthly average of runoff is reaveraged by the monthly average of 12 months, and the month is used as the calculation period. Since the total number of days in different months differs, it must be generalized, meaning treating each month as a certain period of time and a year is regarded as a circle and $0^{\circ}$ at the January runoff vector. $30^{\circ}$ equiangular difference indicates the location of runoff from February to December. If the monthly runoff is decomposed into components in the $x$ and $y$ directions, the vector composition in the $x$ and $y$ directions and the combined total vector $[21,22]$ of the monthly runoff can be expressed as follows:

$$
\begin{aligned}
& R_{x}=\sum_{i=1}^{12} r_{i} \sin \theta_{i}, \\
& R_{y}=\sum_{i=1}^{12} r_{i} \cos \theta_{i}, \\
& R=\sqrt{R_{x}^{2}+R_{y}^{2}},
\end{aligned}
$$

where $R_{i}$ and $\theta_{i}$ are the size and direction of the monthly runoff; $R_{x}$ and $R_{y}$ are the composite vectors in the $x$ and $y$ directions, respectively; $R$ is the composite total vector of $R_{x}$ and $R_{y}$. The concentration degree $R C D_{\text {year }}$ and the 


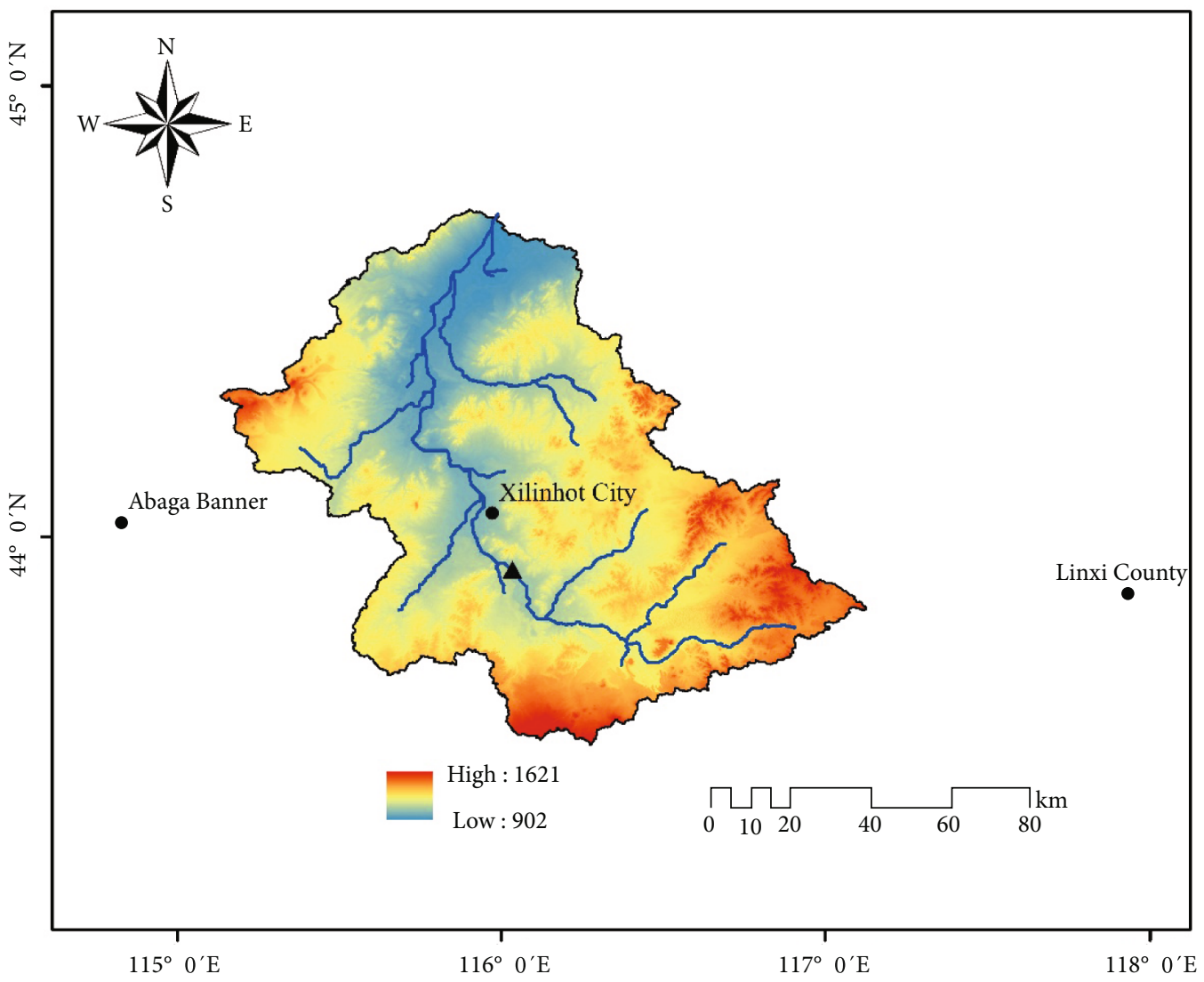

Legend
\ Hydrological station
- Weather station
W Water system

Figure 1: The location of Xilinhe River and related weather stations and hydrological stations.

concentration period $R C P_{\text {year }}$ are defined as follows:

$$
\begin{gathered}
R \mathrm{CD}_{\text {year }}=\frac{\sqrt{R_{x}^{2}+R_{y}^{2}}}{R_{\text {year }}}, \\
R \mathrm{CP}_{\text {year }}=\arctan \left(\frac{R_{X}}{R_{y}}\right) .
\end{gathered}
$$

2.3.1. Mutation Test. The mutation test analysis adopts a combination of Mann-Kendall and Pettitt, a nonparametric test recommended by the World Meteorological Organization (WMO). Using the Mann-Kendall rank test method sometimes detects a lot of mutation points, and there may be false points, so this paper adopts a combination of $\mathrm{M}-\mathrm{K}$ and Pettitt for the mutation study of the distribution sequence within the runoff year to identify the true mutation point position of the sequence.

2.3.2. Comparison Method of Cumulant Slope Change Rate. Assuming that before and after the year mutation happens, the slope of the linear relationship between the cumulative runoff coefficient-year linear relationship is $S_{R i 2}$ and $S_{R i 1}$ (unit: $108 \mathrm{~m}^{3} / \mathrm{a}$ ); the slope of the cumulative precipitation year distribution coefficient-year linear relationship is $S_{P i 2}$ and $S_{P i 1}$ (unit: $\mathrm{mm} / \mathrm{a}$ ), and the contribution rate $C_{P i}$ (unit $\%)$ of precipitation factor to runoff change can be expressed as $[23,24]$

$$
C_{P i}=\frac{100 \times\left(S_{P i 1}-S_{P i 2}\right) /\left|S_{P i 2}\right|}{\left(S_{R i 1}-S_{R i 2}\right) /\left|S_{R i 2}\right|} .
$$

Similarly, the slope of the linear relationship between cumulative potential evapotranspiration before and after the mutation year-year distribution coefficient-year linear relationship is $S_{E i 2}$ and $S_{E i 1}$ (unit: $\mathrm{mm} / \mathrm{a}$ ). The contribution rate of potential evapotranspiration to runoff change $C_{E i}$ (unit: \%) can be expressed as follows:

$$
C_{E i}=\frac{100 \times\left(S_{E i 1}-S_{E i 2}\right) /\left|S_{E i 2}\right|}{\left(S_{R i 1}-S_{R i 2}\right) /\left|S_{R i 2}\right|} .
$$




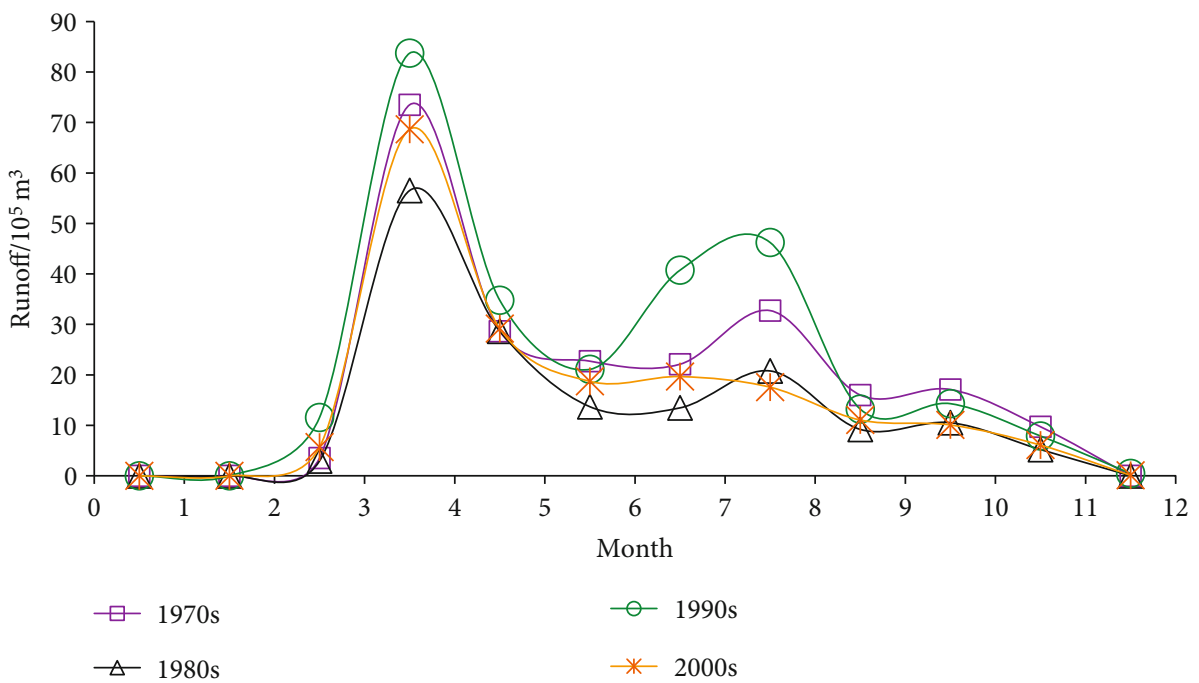

FIGURE 2: Month distribution characteristics in the years of runoff in Xilinhe River.

TABLE 1: Statistic characteristics of annual runoff distribution in Xilinhe River.

\begin{tabular}{|c|c|c|c|c|c|c|}
\hline \multirow[b]{2}{*}{ Period } & \multirow{2}{*}{$\begin{array}{c}\text { Uneven } \\
\text { coefficient } / C_{v}\end{array}$} & \multirow{2}{*}{$\begin{array}{l}\text { Complete adjustment } \\
\text { coefficient } / C_{r}\end{array}$} & \multirow{2}{*}{$\begin{array}{l}\text { Concentration } \\
\text { rate } / \%\end{array}$} & \multicolumn{2}{|c|}{ Concentration period } & \multirow{2}{*}{$\begin{array}{c}\text { Relative } \\
\text { change } /\left(10^{8} \mathrm{~m}^{3}\right)\end{array}$} \\
\hline & & & & $\begin{array}{c}\text { Composite vector } \\
\text { direction }\end{array}$ & $\begin{array}{l}\text { Maximum runoff } \\
\text { time }\end{array}$ & \\
\hline $\begin{array}{l}1960- \\
1969\end{array}$ & 1.3 & 0.470 & 0.487 & 90.6 & April 15 & 0.848 \\
\hline $\begin{array}{l}1970- \\
1979\end{array}$ & 1.25 & 0.437 & 0.508 & 85.8 & April 10 & 0.841 \\
\hline $\begin{array}{l}1980- \\
1989\end{array}$ & 1.33 & 0.486 & 0.567 & 93.3 & April 18 & 0.567 \\
\hline $\begin{array}{l}1990- \\
1999\end{array}$ & 1.24 & 0.465 & 0.538 & 171.25 & July 6 & 0.971 \\
\hline $\begin{array}{l}2000- \\
2010\end{array}$ & 1.57 & 0.571 & 0.671 & 121.1 & May 16 & 0.574 \\
\hline
\end{tabular}

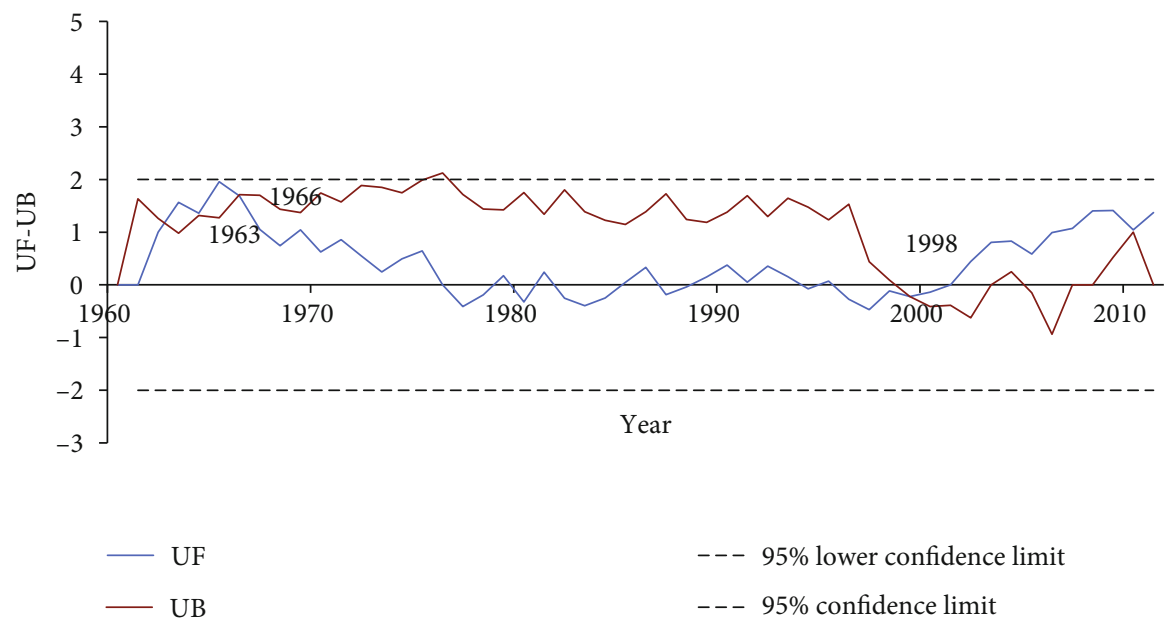

Figure 3: The M-K diagnosis of uneven coefficient. 


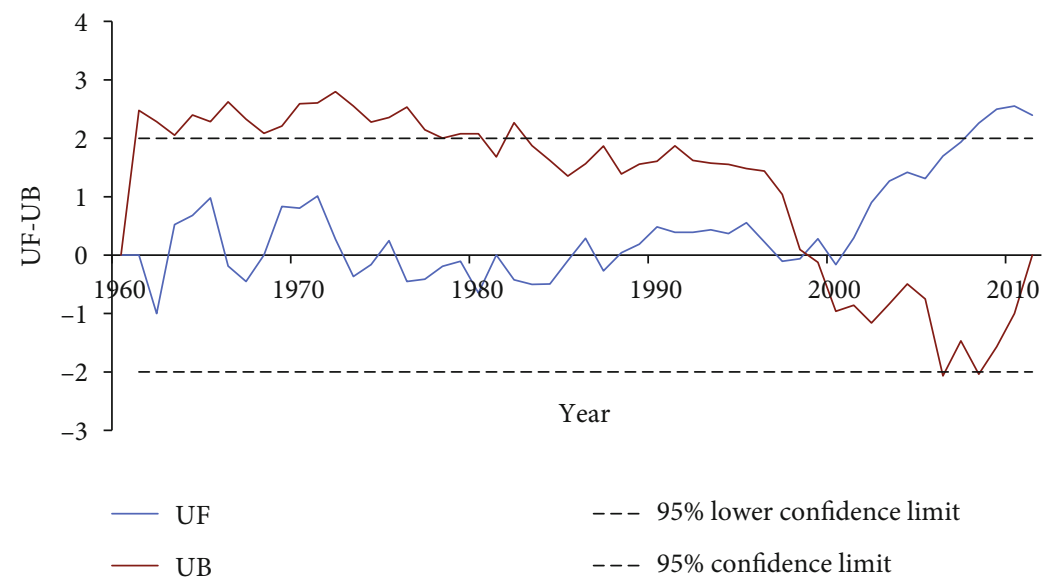

FIGURE 4: The M-K diagnosis of complete adjustment coefficient.

TABLE 2: Variation in characteristic values of runoff seasonal distribution of Xilinhe River in 1960-2010.

\begin{tabular}{|c|c|c|c|c|c|c|c|c|c|c|c|}
\hline \multirow{2}{*}{ Location } & \multirow{2}{*}{ Characteristics } & \multicolumn{2}{|c|}{ Characteristics } & \multicolumn{2}{|c|}{$\begin{array}{l}\text { Trending } \\
\text { analysis }\end{array}$} & \multicolumn{2}{|c|}{ Test on the station } & \multicolumn{2}{|c|}{ Before mutation } & \multicolumn{2}{|c|}{ After mutation } \\
\hline & & $\begin{array}{l}\text { Average } \\
\text { value }\end{array}$ & $\begin{array}{l}\text { Coefficient } \\
\text { of variation }\end{array}$ & Volume & Sig. & Significance & Year & $\begin{array}{l}\text { Average } \\
\text { value }\end{array}$ & $\begin{array}{l}\text { Coefficient } \\
\text { of variation }\end{array}$ & $\begin{array}{l}\text { Average } \\
\text { value }\end{array}$ & $\begin{array}{l}\text { Coefficient } \\
\text { of variation }\end{array}$ \\
\hline \multirow[b]{2}{*}{ Xilinhot } & $\begin{array}{c}\text { Uneven } \\
\text { coefficient }\end{array}$ & 1.339 & 0.216 & 0.208 & 0.041 & 0.0418 & 1998 & 1.15 & 0.178 & 1.57 & 0.307 \\
\hline & $\begin{array}{l}\text { Complete } \\
\text { adjustment } \\
\text { coefficient }\end{array}$ & 0.487 & 0.078 & 0.367 & 0.004 & 0.0073 & 1998 & 0.461 & 0.054 & 0.573 & 0.174 \\
\hline
\end{tabular}

With contribution rates of the above climatic factors, according to the principle of water volume balance, the contribution of human activities to runoff reduction $C_{H i}$ (unit \%) can be expressed as

$$
C_{H i}=100-C_{P i}-C_{E i}
$$

The contribution rate of climate change and human activities to the full adjustment coefficient of the annual runoff distribution can be calculated in the same way.

\section{Results and Discussion}

3.1. Changes in Monthly Distribution of Runoff during the Year. As shown in Figure 2, the distribution characteristics of annual runoff in the Xilinhe River Basin from 1960 to 2010 present obvious "bimodal." From December to next February of the following year, the runoff was basically down to zero due to freezing. Starting from spring, with the temperature going up, the runoff gradually increases, reaching its maximum in April, accounting for about 33\% of the annual runoff. Afterwards, the runoff gradually decreased and increased starting from summer to the second peak in August, accounting for about $13 \%$ of the annual runoff. This is mainly because the Xilinhe River area is cold and snowrich in winter, and only starts to warm up after April, when a large amount of surface ice and snow begin to melt under the sun. Because the temperature in the soil is still lower than the surface temperature, the soil layer is still frozen, making it difficult for the snowmelt water to infiltrate into the soil layer, causing a large amount of snowmelt water to flow into the river, forming a spring flood [25]. As the soil temperature goes up in May, the snowmelt water began to seep, and the runoff decreased. June to August usually witness the most abundant rainfall in the Xilinhe River Basin, reaching 61\% of the annual rainfall; hence, the second peak comes. After mid-October, the Xilinhe River Basin will enter the freezing period.

3.2. Statistical Characteristics of Annual Runoff Distribution. In order to further study the characteristics of the runoff distribution in the Xilinhe River Basin during the year, statistical analysis was made on the uneven coefficient, complete adjustment coefficient, concentration, concentration period, and relative change range of runoff, and the results are shown in Table 1. The watershed runoff uneven coefficient and complete adjustment coefficient in the 2000s are the largest, followed by those in the $80 \mathrm{~s}$. The runoff uneven coefficients and full adjustment coefficients in the 60s-70s and 90s are smaller. For runoff concentration, the highest concentration happened in the 2000s, followed those in 80 s, and the one in the 60 s is the smallest. The reason is that around 2000, Xilinhot City (accounts for approximately $63.9 \%$ of the basin area) developed rapidly. More people came to the city as the economy roared and more exploitations to groundwater to satisfy increasing need on the drinking of surface water, changing long-term runoff distribution pattern with natural factors as the main controlling factor. From the perspective 


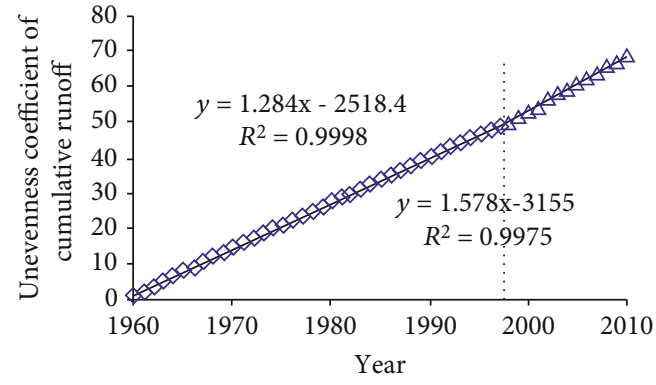

FIgURE 5: Unevenness coefficient of cumulative runoff.

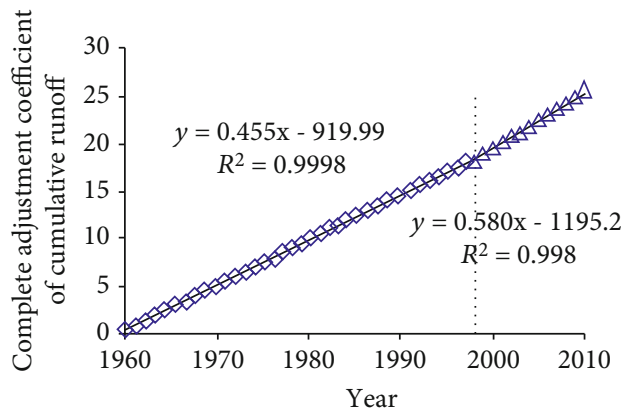

Figure 6: Complete adjustment coefficient of cumulative runoff.

of changes in the concentration period, the maximum runoff from 60 s to 80 s occurred in April, and the maximum runoff during the $90 \mathrm{~s}^{\prime}$ concentration period is now in July. The main sources of runoff replenishment in the Xilinhe River Basin are melting ice and snow and atmospheric precipitation. The melting of ice and snow mainly starts in April and tends to form a large amount of surface runoff in April. July is the rainiest season of the year and tends to form a large amount of surface runoff. However, the maximum runoff occurred in May during the 2000s' concentration period. The above situation also shows that especially after the 2000s, the increasing human activities seriously affected the runoff distribution.

3.3. Diagnosis of Variation Point of Uneven Distribution Coefficient and Full Adjustment Coefficient of Annual Runoff Distribution. As shown in Figure 3, the M-K test was applied to check the coefficient of uneven distribution of runoff in the Xilinhe River Basin for abrupt changes. The results show that there are three intersections between UF and $\mathrm{UB}$ of the coefficient of uneven distribution of runoff in 1963, 1966, and 1998. In order to verify the mutation, this paper applied the Pettitt method for further test. The Pettitt method test results show that the mutation only happened in 1998, and the $P$ is $0.0418<0.05$, and the test result is significant. The $\mathrm{M}-\mathrm{K}$ test result of the distribution of the full adjustment coefficient within the year showed that UF and UB only had one intersection point, and further test by Pettitt method showed that $P$ was $0.0073<0.05$, and the test result was significant. As shown in Figure 4, it shows that 1998 is the mutation point of the uneven distribution coefficient of runoff and the complete adjustment coefficient of the year. From Table 2, we can see that the uneven coefficient and

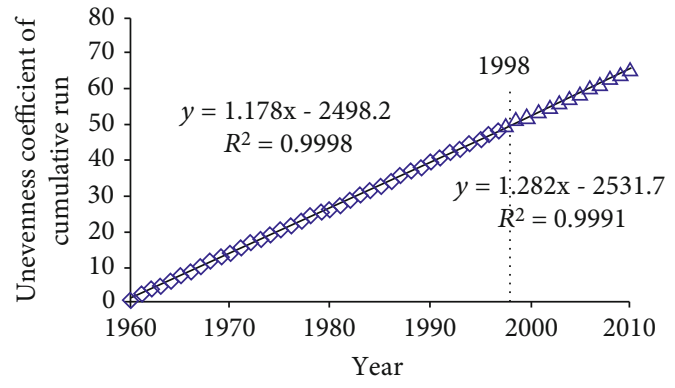

Figure 7: Unevenness coefficient of cumulative run.

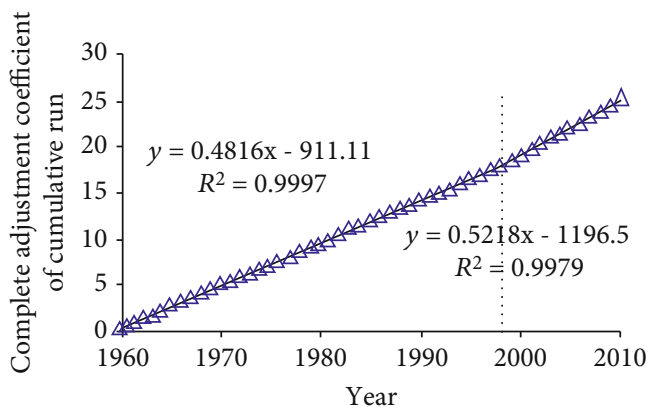

Figure 8: Complete adjustment coefficient of cumulative run.

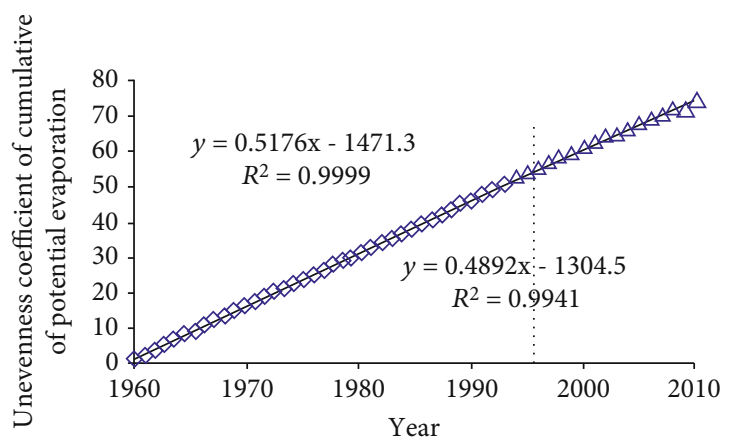

Figure 9: Unevenness coefficient of cumulative of potential evaporation.

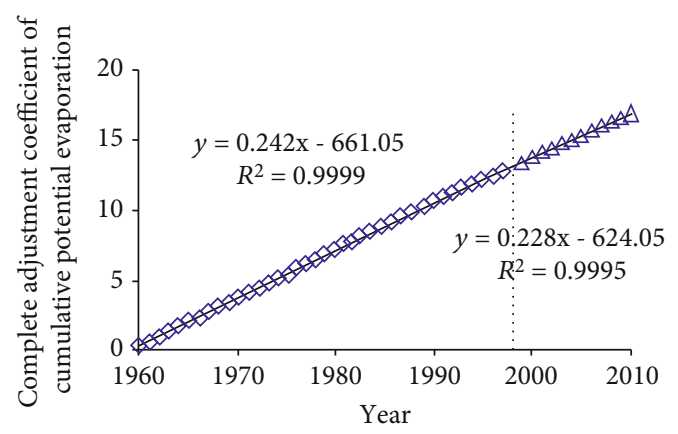

Figure 10: Complete adjustment coefficient of cumulative potential evaporation. 
TABLE 3: Change ratio of the slopes of accumulative characteristic values of runoff, precipitation, and potential evaporation seasonal distribution in1960-2010.

\begin{tabular}{|c|c|c|c|c|c|c|c|c|}
\hline \multirow[b]{2}{*}{ Location } & \multirow[b]{2}{*}{$\begin{array}{l}\text { Influence } \\
\text { factor }\end{array}$} & \multirow[b]{2}{*}{$\begin{array}{l}\text { Time } \\
\text { period }\end{array}$} & \multicolumn{3}{|c|}{ Uneven coefficient } & \multicolumn{3}{|c|}{ Complete adjustment coefficient } \\
\hline & & & $\begin{array}{l}\text { Cumulative slope } \\
\text { rate }\end{array}$ & $\begin{array}{l}\text { Changing } \\
\text { volume }\end{array}$ & $\begin{array}{c}\text { Changing } \\
\text { rate } / \%\end{array}$ & $\begin{array}{c}\text { Cumulative slope } \\
\text { rate }\end{array}$ & $\begin{array}{l}\text { Changing } \\
\text { volume }\end{array}$ & $\begin{array}{c}\text { Changing } \\
\text { rate } / \%\end{array}$ \\
\hline \multirow{6}{*}{ Xilinhot } & \multirow{2}{*}{ Runoff } & $\begin{array}{c}1960- \\
1998\end{array}$ & 1.284 & & & 0.455 & & \\
\hline & & $\begin{array}{l}1998- \\
2010\end{array}$ & 1.578 & 0.294 & 22.9 & 0.580 & 0.125 & 27.5 \\
\hline & \multirow{2}{*}{ Rainfall } & $\begin{array}{c}1960- \\
1998\end{array}$ & 1.282 & & & 0.5218 & & \\
\hline & & $\begin{array}{l}1998- \\
2010\end{array}$ & 1.178 & 0.104 & 8.11 & 0.4816 & 0.04 & 8.35 \\
\hline & \multirow{2}{*}{ Evaporation } & $\begin{array}{c}1960- \\
1998\end{array}$ & 0.5176 & & & 0.2423 & & \\
\hline & & $\begin{array}{c}1998- \\
2010\end{array}$ & 0.4892 & 0.0284 & -5.48 & 0.2283 & 0.014 & -5.78 \\
\hline
\end{tabular}

TABLE 4: Relative contribution of climate change and human activities to the change in characteristic values of runoff seasonal distribution in Xilinhe River.

\begin{tabular}{|c|c|c|c|c|c|c|c|c|}
\hline \multirow[b]{2}{*}{ Location } & \multicolumn{4}{|c|}{ Relative contribution to the uneven coefficient/\% } & \multicolumn{4}{|c|}{ Relative contribution to the complete adjustment coefficient $/ \%$} \\
\hline & Rainfall & $\begin{array}{c}\text { Potential } \\
\text { evaporation }\end{array}$ & $\begin{array}{l}\text { Climate } \\
\text { change }\end{array}$ & $\begin{array}{l}\text { Human } \\
\text { activities }\end{array}$ & Rainfall & $\begin{array}{c}\text { Potential } \\
\text { evaporation }\end{array}$ & $\begin{array}{l}\text { Climate } \\
\text { change }\end{array}$ & $\begin{array}{l}\text { Human } \\
\text { activities }\end{array}$ \\
\hline Xilinhot & 35.41 & -23.93 & 11.48 & 88.52 & 30.36 & -21.01 & 9.35 & 90.65 \\
\hline
\end{tabular}

the complete adjustment coefficient of the annual runoff distribution have mutations. The average value and the coefficient of variation before the mutation are smaller than that after the mutation. It can be seen that the interannual variability of runoff in this basin increases drastically, and the risk of drought and flood increases; this is unfavorable to the use of water resources.

3.4. Quantitatively Decompose the Contribution Rate of Climate Change and Human Activities to Changes in the Distribution Characteristics of Runoff during the Year. Taking 1998 as the turning point, the Xilinhe River Basin's intraannual runoff distribution characteristic value was divided into two periods, 1960-1998 and 1998-2010, and linear regression analysis was performed on the cumulative runoff unevenness coefficient and complete adjustment coefficient between the years (please see Figures 5 and 6 for details). It is safe to say that changes in the annual distribution of runoff in the basin from 1960 to 1998 were basically influenced by climate change with minor effects from human activities. After that, the changes have been affected by both climate change and human activities. Since 1998, human activities have been greatly expanding in the basin. From Figures 510 and Table 3 , we can see that the slope of the abrupt change of the runoff distribution coefficient and the full adjustment coefficient during the year is greater than that before the change, while the slope of the precipitation and potential evapotranspiration after the change of the full adjustment coefficient is less than before the mutation. Moreover, the variation of the uneven distribution coefficient and the slope of the complete adjustment coefficient of runoff during the year are much higher than that of rainfall and potential evapotranspiration. According to formula (9)-(11), the contribution rate of climate change and human activities to the change in the distribution characteristics of the runoff in the Xilinhe River Basin could be conducted, and the results are shown in Table 4 . It can be seen from Table 4 that the relative contribution rate of human activities to the uneven distribution coefficient and the full adjustment coefficient of runoff during the year is much greater than that of climate change. Potential evapotranspiration inhibits the uneven distribution coefficient and complete adjustment coefficient of runoff during the year, and rainfall aggravates it. Human activities are the main cause of changes in the distribution of runoff during the year by changing part of the water cycle.

\section{Conclusion}

(1) The monthly distribution of runoff in the Xilinhe River Basin is extremely uneven during the year, with the highest uneven distribution coefficient of 2.21 (2005), and the runoff is mainly concentrated in April to September. From the perspective of seasonal changes, runoff is mainly concentrated in summer whereas zero runoff in winter. The distribution characteristics of runoff during the year are obviously 
"bimodal," which is different from the single-peak characteristics of the annual runoff distribution in Yingluoxia [19] and Kaidu River Basin [20]. This is mainly due to the melting of the heat-sensitive surface caused by the latent heat generated by solar radiation and evaporation and the temperature difference between the snow and the atmosphere in April. But since the soil's permeability has not fully recovered after being frozen for a long time, the permeability of the underlying surface is weaker than the rate of snowmelt runoff, resulting to the "first peak"

(2) It can be seen from the analysis results of the statistical characteristics of runoff distribution within the year that the uneven coefficient, complete adjustment coefficient, concentration degree, and the concentration period from 60 s to 90 s are relatively stable with minor changes. The maximum runoff occurs in April or July, which coincides with the monthly distribution of runoff during the year. The uneven coefficient, complete adjustment coefficient, and concentration of 2000s are significantly higher than those in the 1960s-1990s with abnormal concentration period. The runoff process is the result of the comprehensive effect of climate change and the underlying surface of the basin. The runoff observed by hydrological stations shows the result influenced by climate change, land use change, water volume adjustment, and water consumption of water conservancy projects. Around 2000, Xilinhot City (approximately 63.9\% of the watershed area) developed vigorously with obvious expansion, changing land use patterns and intensifying surface water drinking and groundwater extraction. This has changed the long-term runoff distribution pattern with natural factors as the main controlling factor. Extensive human activities have affected the distribution of runoff during the year, making it more difficult for human to control

(3) The uneven distribution coefficient and the complete adjustment coefficient of runoff during the year, after combined with Mann-Kendall and Pettitt, show a time-series variation point in the sequence, both happened in 1998. Climate change and human activities contributed $11.48 \%$ and $88.52 \%$ and $9.35 \%$ and $90.65 \%$ to the uneven distribution coefficient and full adjustment coefficient of the runoff in the Xilinhe River Basin, respectively. Human activities are the main driving factors for changes in the distribution of runoff in the Xilinhe River Basin. The contribution rate of human activities to the annual distribution of runoff analyzed in this paper includes the storage regulation of water conservancy projects, industrial water consumption, and the change of land use types. Due to the lack of relevant detailed information and the intricate interactions between factors, how to further quantitatively decompose the influence of these factors on the distribution characteristics of runoff during the year remains challenging for research and calls for further discussion in the future

\section{Data Availability}

The data used to support the findings of this study are included within the article.

\section{Conflicts of Interest}

The authors declare that they have no conflicts of interest.

\section{References}

[1] X. P. Ma, H. Y. Bai, and Q. L. Hou, "Runoff change of Bahe River basin in Qinling mountains and its influencing factors," Resources Science, vol. 34, no. 7, pp. 1298-1305, 2012.

[2] Q. L. Hou, H. Y. Bai, and Y. Y. Ren, "Analysis of variation in runoff of the main stream of the Weihe River and related driving forces over the last 50 years," Resources Science, vol. 33, no. 8, pp. 1505-1512, 2011.

[3] X. Q. He, B. Zhang, and L. W. Sun, "Contribution rates of climate change and human activity on the runoff in upper and middle reaches of Heihe River basin," Chinese Journal of Ecology, vol. 31, no. 11, pp. 2884-2890, 2012.

[4] Z. S. Chen, Y. N. Chen, and C. C. Xu, "Change trend and prediction of annual runoff in main stream area of the Tarim River in recent 50 years," Arid Land Geography, vol. 1, pp. 43-51, 2011.

[5] J. Q. LI, Y. N. Chen, and W. H. Li, "Variation features of precipitation and runoff of the middle-small rivers of northern piedmont of Tianshan Mountains:a case of Jinghe River," Arid Land Geography, vol. 33, no. 4, pp. 615-622, 2010.

[6] J. Y. Zhang, G. Q. Wang, and J. L. Jin, "Evolution and variation characteristics of the recorded runoff for the major rivers in China during 1956-2018," Advances in Water Science, vol. 31, no. 2, pp. 153-161, 2020.

[7] Z. X. Bao, J. Y. Zhang, X. L. Yan et al., "Quantitative assessment of the attribution of runoff change caused by four factors in the Haihe River basin," Advances in Water Science, vol. 41, no. 11, pp. 16-23, 2020

[8] X. H. Gao and Y. X. Gao, "Study on sediment and runoff change in Wuding River Basin," Groud Water, vol. 42, no. 6, pp. 167-169, 2020.

[9] L. I. Miao, Y. A. N. Si-rui, L. I. U. Qiang, Z. H. A. N. G. Junlong, and Y. U. A. N. Xiao-min, "Analysis on streamflow processes response to extreme meteorological drought in the baiyangdian basin China," Environmental Engineering, vol. 38, no. 10, pp. 14-20, 2020.

[10] X. J. Tu, X. H. Chen, and L. H. Zhang, "Annual distribution of streamflow with different identifications of time intervals," Ecology and Environmental Sciences, vol. 20, no. 1, pp. 119123, 2011.

[11] M. Palmer and A. Ruhi, "Linkages between flow regime, biota, and ecosystem processes: implications for river restoration," Science Letter, vol. 365, no. 6459, pp. 1538-9111, 2019.

[12] Q. Liu, X. Ma, S. Yan, L. Liang, J. Pan, and J. Zhang, "Lag in hydrologic recovery following extreme meteorological drought events: implications for ecological water requirements," Water, vol. 12, no. 3, p. 837, 2020.

[13] M. Saft, M. C. Peel, A. W. Western, J.-M. Perraud, and L. Zhang, "Bias in streamflow projections due to climateinduced shifts in catchment response," Geophysical Research Letters, vol. 43, no. 4, pp. 1574-1581, 2016. 
[14] T. Apurv, M. Sivapalan, and X. Cai, "Understanding the role of climate characteristics in drought propagation," Water Resources Research, vol. 53, no. 11, pp. 9304-9329, 2017.

[15] S. Z. Hung, Q. Huang, and Y. M. Wang, "Change in runoff seasonal distribution and the decomposition of contribution rate of impacting factors in the Wei River," Progress in Geography, vol. 33, no. 8, pp. 1101-1108, 2014.

[16] G. E. Petts, M. A. Bickerton, and C. Crawford, "Flow management to sustain groundwater-dominated stream ecosystems," Hydrological Processes, vol. 13, pp. 497-513, 1999.

[17] D. M. Hannah, B. P. G. Smith, and A. M. Gurnell, "An approach to hydrograph classification," Hydrological Processes, vol. 14, pp. 317-338, 2000.

[18] A. C. Disalvo and S. C. Hart, "Climatic and stream-flow controls on tree growth in a western Montane riparian forest," Environmental Management, vol. 30, no. 5, pp. 678-691, 2002.

[19] Q. L. Guo, Y. S. Yang, and X. Y. Chang, "Annual variation of Heihe River runoff during 1957-2008," Progress in Geography, vol. 30, no. 5, pp. 550-556, 2011.

[20] J. Xue, L. H. Li, and X. M. Li, “Annual distribution of precipitation and runoff and the synchronicity of their variations in the Kaidu river basin," Journal of Arid Land Resources and Environment, vol. 28, no. 12, pp. 99-104, 2014.

[21] L. J. Zhang and Y. F. Qian, "Annual distribution features of precipitation in China and their interannual variations," Acta Meteorologica Sinica, vol. 17, no. 2, pp. 146-163, 2003.

[22] X. M. Li, F. Q. Jiang, and L. H. Li, "Spatial and temporal variability of precipitation concentration degree and concentration period in Xinjiang, China," International Journal of Climatology, vol. 31, pp. 1679-1693, 2011.

[23] S. J. Wang, Y. C. Yan, and M. Yan, "Contributions of precipitation and human activities to the runoff change of the Huangfuchuan drainage basin: application of comparative method of the slope changing ratio," Acta Geographica Sinica, vol. 67, no. 3, pp. 388-397, 2012.

[24] S. J. Wang, L. Li, and M. Yan, "The contributions of climate change and human activities to the runoff yield changes in the middle Yellow River Basin," Geoeraphical Research, vol. 32, no. 3, pp. 395-402, 2013.

[25] C. Y. Duan, S. Zhang, and J. R. Li, “Analysis on rainfall-runoff characteristics and simulation of the different hydrologic year runoff of Xilinhe River in Inner Mongolia based on SWAT model," Research of Soil and Water Conservation, vol. 21, no. 5, pp. 292-297, 2014. 